\title{
ANALYSIS ON HOME ENVIRONMENT AND SOCIAL MATURITY OF SENIOR SCHOOL STUDENTS
}

\author{
Dr J John Sunil Manoah \\ Academic Adviser \\ Vethathiri Maharishi Hr. Sec. School, SVG Puram, Tamil Nadu, India
}

\begin{abstract}
Even the phrase "Feel at home" will not allow oneself to feel a place as Home, unless it is a home. A home kind of environment is not possible to be provided in $100 \%$ at school, since school is the only place where one can promote their knowledge with little rules and conditions. A study says that only at school children kept their mind open in order to receive something from academic background. Even at home there are some rules and conditions to the children for e.g. they can't use the living room as a rest room, likewise even at school some conditions are carried on in different perspective only for the welfare and betterment of children. When there in a development in someone's maturity then it is possible for the students to the school as their second home and to feel the home kind of environment, adding to the support of management and teachers home environment is certainly on the cards.
\end{abstract}

Keywords - Maturity, Environment, Individual

\section{INTRODUCTION}

Social Maturity is not a question about age factor, whereas many people believes that age plays a vital role in attaining social maturity, which is not true at all. We have taken two different points for discussion (i) Home environment, (ii) social Maturity, the first point can be classified into two forms one is about Home and the second is about having home kind of environment at school, likewise the second point also can be classified into two forms, one is about maturity and second one is about getting maturity from social background. Let us discuss the outline of these points, since we are not going to step into the brief study.

\section{COMMON UNDERSTANDINGS AND FINDINGS}

\section{A. ABOUT HOME}

Home is a place where everyone could be more comfortable than any other place. At home we believe that we have our freedom to do things we like the most, no will questions our freedom at home, this is the scenario for most of the students nowadays as they were treated with love and affection by their parents. Another benefit that one possesses at home is called 'Privacy' which is intended to have a standard of social maturity to understand the term. Indeed freedom and privacy is certainly not possible to get from anywhere as like home, hence it is understood that home is the best place for comfortable living. When we talk about freedom and privacy it is a matter of mind and matter, our mind has to feel that we are given the freedom and privacy, if our mind is not feeling so then even if freedom and privacy really exists it is still not for us. Hence mind is the only factor to determine and realize the existence of freedom and privacy.

\section{B. HOME KIND OF ENVIRONMENT}

When we say home environment is not that just, it is home kind of environment, since no place can compete with home. My study is all about on how to provide home kind of environment to the school students at school which will make them to feel comfortable. I believe only the comfortable environment will give more room for the students to have better learning. In various parameters we can consider the environment at school.

Environment of a classroom differs from subject to subject.

Environment differs from teacher to teacher.

Environment differs from season to season (Based on climatic conditions of a region which too makes an impact on students mind)

Environment differs from session to session (Morning session, Noon session, Afternoon session, Evening Session and Night Session)

Environment differs from period to period.

A detailed study will be carried on in the main thesis on the above mentioned parameters which will be undertaken with the assistance from case study analysis.

\section{ABOUT MATURITY}

Maturity is defined as a state of development that occurs in one's mental growth that can be determined by the capability of understanding one's role, responsibilities, status and condition. I've read an article about "18 signs of maturity" from a local magazine from which one sign inspires me more which can be duly considered for senior students that is "When you learn to let go, accept the situation and move on" is called maturity. If we see in this perspective then it states 


\section{International Journal of Engineering Applied Sciences and Technology, 2020 Vol. 4, Issue 9, ISSN No. 2455-2143, Pages 212-216 \\ Published Online January 2020 in IJEAST (http://www.ijeast.com)}

maturity means letting things go when it wanted to go out of our life and then accept the situations that we are presented in. Maturity is certainly a question in students' life, it's very rare nowadays notwithstanding that the students can understand their role, responsibility and situation. It takes many years for the students to understand the efforts of a teacher and the parents especially that were given to them when they were in students' life. Maturity again is a matter of mind which is been shaped by so many factors like,

\section{Age}

\section{Society}

Family Background

Culture

\section{Place of Education}

Indeed maturity varies from person to person based on the above mentioned parameters; we shall have a deep analysis about those factors in the complete study.

\section{MATURITY WITH SOCIAL BACKGROUND}

It is said that "man is a social animal", which cannot be declined by anyone. The only thing that differ us from the animals is the social maturity. I didn't mean here to say only about maturity, hitherto animals do possess maturity, whereas we the humans posses the maturity with social background. The society plays a vital role in shaping up once maturity from which the word social is raised from. A student cannot separate himself from the society, the family, friends along with the society of a student enables the maturity level, the word social is more than the subject as it means as a characterization to devote friendly companionship with others. In my perspective I define social maturity is "when we understand that everyone is right in their own perspective" if we do so then we can have rightly pointed companionship with other which can be called as socialism. In some scenario the social background of the students makes them to suffer from social problem, which eventually blocks the students in attaining maturity. The term social maturity can further be described as,

\section{Basic Manners \\ Common Sense}

Self Discipline

\section{Self Respect}

Maintenance of Dignity, Decorum and many more

\section{E. THE INFLUENCE OF BASIC MANNERS OF A STUDENT AT SCHOOL AND HOME}

Age and Experience plays a vital role in shaping one's manners. Manners are actions that one bears within their personality that reflect their own custom, habitual, and way of living. Many may think that the manners are usually born in a child after attaining into the school domain, which may be true is some scenarios but not all in cases. Lets us see the scenario in which the student has no option to acquire manners at home.

Scenario 1: When the children are born orphan just by losing their parent moment after the birth, since the child has to be raised by some person who are not their parents and the possibilities to be ignored are more, which will make the child to disperse manners in their life.

Scenario 2: When the children are raised in streets out of their own, without being in someone's custody.

Scenario 3: When the parents of the child are illiterate and not having any awareness in subject of manners.

Scenario 4: When the parents are interested in raising their children in good custom, especially when are in mindful of their own and personal affairs.

Likewise many scenarios can be discussed which could be the causes for the children to miss manners in their life. All the above discussions are carried on in order to understand that school is the not the only place for the children to acquire manner, from this we can understand that the child begin to acquire manner at home first before school. Nowadays most of the schools maintain uniformity in teaching manners to the children, if that is the case every student that comes out of one particular school must be uniform in their manner, which is not possible at, since the truth is 'manners' differs from student to student and child to child.

Manners help the students to understand a lot about their culture, society, background and importance of family values, once the student start to display their manners, then the state of maturity is attained by the child in default.

\section{F. THE INFLUENCE OF BASIC COMMONSENSE OF A STUDENT AT SCHOOL AND HOME}

The natural intelligence in understanding the situation of practicality and reality and acting according to the situation is called as commonsense. Commonsense is a very essential tool for every individual in order to gain respect and dignity in the society, since the modernized culture of the present world demands every citizen to be mindful of the situation and to act without affecting others liberalism and immunity. Hence, there is a big expectation from everyone that they wish to see the whole universe act with commonsense. Commonsense cannot be taught in theoretical method, rather is can be taught at home and school by explaining the practical reality of a particular situation or by making someone to understand the situation from both the sides and make them to insight the situation in common perspective. Either it is a home or school it is mandatory for everyone to behave with commonsense. Nowadays most of the parents tend to teach their children some basic values of their culture and family before the child joins a school. Most of the schools nowadays tend to teach the moral values, manners and methods to apply common sense in reality life, since the awareness has gained must attention from the society and started to believe that only by working in the mental ability of the children knowledge cannot be attained 


\section{International Journal of Engineering Applied Sciences and Technology, 2020 Vol. 4, Issue 9, ISSN No. 2455-2143, Pages 212-216 \\ Published Online January 2020 in IJEAST (http://www.ijeast.com)}

which alone will lay platform to attain wisdom. In the middle of all these learning environments about commonsense, there are still some lapses which will prevent and hinder the children in learning basic common sense.

When children are born and raised up in barbarian culture, thou the term 'Barbarianism' is seen as faded nowadays, it still exist in most part of the world.

When children are grown up in street environment by missing the care take of parents and understood the world in the own perspective.

When children are trained and mentored by people who are underdeveloped in commonsense.

When children grew up in an environment where there is no understanding about the universe.

When someone is mentally ill and little percentage which is not visible to the external sight, prefers themselves to stay in their own privileges.

It is universally accepted that the presentation of commonsense in one's actions enable them to access amiable with everyone. If someone was found and occurred limited in commonsense, it is nature of everyone to keep aside of the people. Hence, it is implicit that commonsense is seen in wider perspective in shaping one's maturity.

\section{G. THE INFLUENCE OF SELF-DISCIPLINE OF A STUDENT AT SCHOOL AND HOME}

Before understanding about self-discipline it is needed to know about discipline which means as training or applying an act according to the rules and procedure. It is also understood that discipline is a performance of an individual within the conditions and constrains. The process of maintaining a set of rules in unique and exception method which draws the deference of others is considered as self-discipline. The notion of self-discipline is different from country to country and people to people, hence, self-discipline cannot be common among everyone. It is diverse in nature and structure; it depends upon the individual to exercise self-discipline according to their own format. As like the other maturity sources self-discipline is also taught to the children at home and school in specific, since school cannot function with standard without maintaining self-discipline. Every Institution will have their own set of rules and regulations which may differ from institution to institution, the rules and regulations of the institutions are framed based upon their belief, faith and preference but still every institution will uphold to some set of rules and regulations which will enable the students to maintain self-discipline in their acts. There are lots of barriers for the students to acquire self-discipline in their personal life.

In India it is very common to see children raised up in street, as there are no proper caretakers for them, those children will learn to grow by their own understanding of reality life, which will be highly influenced by the corrupted society, hence most of the children those who grow up in streets may not attain self-discipline in their life.
Children who are born to the parents those who have strong connection with ghetto.

Children who are not getting education and forced to look after work affairs.

Children who are raised by the parents who doesn't think off for the welfare of the society.

\section{H. THE INFLUENCE OF SELF-RESPECT OF A STUDENT AT SCHOOL AND HOME}

There is a thin gap between respect and self-respect which is merely misinterpreted by most, respect is an honour that a person gets from others for their position, role, designation, status, and class. Whereas self-respect is quite different as it the manner that one behaves to which will make others tend to respect. Respect can be easily gained by any individual even by holding sound monetary status, but the self-respect cannot be gained like that, it is earned by the individual's behaviour. There are many practices and policies of an individual needs to cultivate which alone can gain self-respect. Especially a child who is inbound with natural instinct of soft skills can easily gain self-respect in the society but the child who is not gifted with natural instinct of soft skills can't acquire the selfrespect to which an external support like guiding, counseling, mentoring, training and teaching are required. If the children are provided the above said support then the secondary chances are more to emulate themselves to be self-respected. Lets us discuss some of the hindrances for the children to forfeit self-respect.

In order to acquire self-respect at first the children must be taught to respect others whole heartedly without any inequity and bias shown to the people who deserves respect. Hence when a child in not taught to respect others whole heartedly the possibilities are more for the child to miss self-respect in life.

Secondly the child must be taught to have big respect for their own to their physic, personality, nature, knowledge and behavior, when the feel good about themselves then the possibilities are more for the child to acquire self-respect.

When a child grew up in a condition where the child never seen anyone respecting each other the possibilities are highly less to learn self-respect.

\section{THE INFLUENCE OF DIGNITY AND DECORUM}

Both the terms dignity and decorum cannot be learned or procured it has to be self generated within oneself, thou the literary meaning for dignity and decorum are separate, they both belong to same family in style and nature. The nobility maintained in a character is called as dignity, it is very simple to express but hard to pursue, as the pursuance of dignity is to be assigned by the outsiders to the individuals. Though it is self generated, it has to be acknowledged and recognized by the outsiders, even thou if an individual believes that he pursues dignity in his life which is not recognized by others it is still not considered as dignity, hence dignity has to be 
awarded from outsiders to an individual. Pleasing the outsider is the hardest part of the life it takes tremendous sense of application which requires the maintenance of balance thought out the life, only then the term dignity can be earned by the individuals. The other phase decorum is very similar is denotes the behavior of a person's dressing style and speech. When we talk about dressing they are various kinds of style, since the modernism and post-modernism culture had given exemption and flexibility to wear any of its kind. It doesn't matter what type of costume that one wears but decorum is understood in terms of decency is expose of human body and skin, how much that one had covered the body of himself/herself is understood as decorum in terms of dressing, it still doesn't matter what kind of dress they wear, unless it covers most of the body parts it is understood that the individual has acquired decorum which tends them as matured. As like dressing sense the speech of a person also matters in terms of gaining decorum, "No matter how much we hide our identity the moment we start opening our mouth everything will be disclosed". Indeed it's very true in most of the individuals; hence it is better for someone to keep their mouth shut rather opening and disgracing.

\section{J. THE RAISE IN MATURITY WITHIN FAMILY BACKGROUND}

The word maturity is different perspective in terms of family, whereas in society everyone has got some limits which are bounded within the boundaries of fundamental rights, but in the case of family, the liberation occurs little more and the person will tend to take more privileges within one's family. Social maturity cannot be acquired by a person if he/she belongs to nuclear family. But the individuals from joint family got heavy chances to understand and gain social maturity within their family itself, as they have to face lot of diverse situations which will tend them to act differently according to the circumstances. Maturity is subjected according to the specific condition and plight; some may get chances in life to acquire specific kind of maturity in specific area and some won't, hence maturity is completely boarded as per the chances that one get in their life. People who are living in a joint family has no other go rather learning to adapt and act according to the person, place and time, whereas the people living in nuclear family will rarely get chances to understand other people and adaptability. It doesn't mean that they won't mingle or deal a situation where they meet more number of people at home; sometimes even the people from nuclear family will have scenarios to meet lot of people at home but that is only for a short period, as the behavior of the people differ from when are together for a short period and for a long period. The background of the family and its practices, pursuance of traditionalism, culture, and orthodox logy drives some individuals to learn and acquire maturity by default, but some individual's family background won't provide the platform to acquire maturity as most of them would have come illiterate and generated in dregs society, who will never find any drive to acquire maturity in their life. This is one of the reasons for the universe to witness much of the people lacking in maturity.

\section{K. MATURITY IS THE ULTIMATE AWARENESS TO INSIST THE INTEREST TOWARDS SCHOOL}

School going children can be classified into two types based upon our article.

1. Children those who like attending schools despite of so many hindrances.

2. Children who don't like attending schools although there are so many comfort zones.

Indeed it is been observed by most of the teachers who work in a school, that there are many children attending school regularly despite of so many hindrances like:

Children affected with poverty

Children affected with social problems

Children affected with homelessness

Children affected with psychological issues

Children affected with various kinds of abusive

As said earlier it is also been observed that despite of having several comfort features at home some of the enlisted children don't show interest in attending school:

Children who had bitter experiences with teachers in the primary level

\section{Children who had been sexually abused at school}

Children who had been mocked or ill-treated by their peers

Children who had physical discomfort in formal way of handling by the teacher

Children who felt some psychological discomfort at school environment

Either the hindrances or the contentment, it is observed that most of children who prefer to attend school are good at personal maturity. That kind of maturity is not learned or experienced, it is self born and self generated. As the children are matured enough to understand the value of education and the importance of gaining knowledge, the motivation is absolutely

inborn.

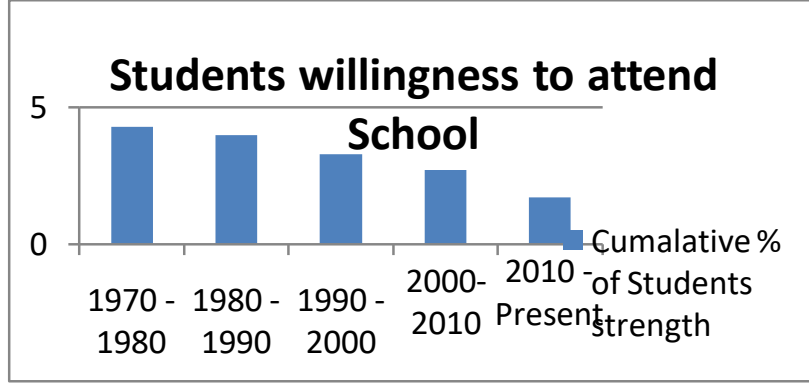

Table -1 Changing demographics of students' willingness to attend school decade wise. 


\section{SOURCE: the74million.org}

\section{CONCLUSION}

Classroom must be a place in which the student must feel great being, as I used the word great it is more than the feel of happiness, it should not happen for one or two periods in a day it must happen in all the periods, it is a responsibility of all the subject teachers to take care of the classes and their students in such a format, the primary responsibility holds in the hands of the head of institutions, who alone can make such a kind of environment possible.

\section{REFERENCES}

1) Manoah. J John. "Formulas for being expertise in classroom and students handling." IRA International Journal of Education and Multidisciplinary Studies (ISSN 2455-2526) [Online], 3.1 (2016): n. pag. Web. 4 Oct. 2016

2) Manoah, John Sunil. "The scheme of implementing Active Learning Methodologies for the students of rural areas." IJAR Indian Journal of Applied Research (ISSN 2249-555X) Vol 1, Issue 10 Oct. 2016

3) Manoah, J. J. S. J. (2015). Formulas for Effective Teaching and Classroom Management. Language in India, 15(2).

4) Rasappan, Suresh \& Manoah, John. (2018). Activity based learning for slow learners in colleges through mollycoddle method. Indian Journal of Public Health Research \& Development. 9. 1957. 10.5958/09765506.2018.01739.4.

5) Keating, D. P. (1978). A search for social intelligence. Journal of Educational Psychology, 70(2), 218-223. https://doi.org/10.1037/00220663.70 .2 .218

6) Arnett J (1993) Reckless behavior in adolescence: a developmental perspective. Developmental Review 12: 339-373.

7) Giedd JN, Blumenthal J, Jeffries NO, Castellanos FX, Liu H, et al. (1999) Brain development during childhood and adolescence: a longitudinal MRI study. Nature Neuroscience 2: 861-863.

8) Gogtay N, Giedd JN, Lusk L, Hayashi KM, Greenstein D, et al. (2004) Dynamic mapping of human cortical development during childhood through early adulthood. Proc Natl Acad Sci U S A 101: 8174-8179.

9) Galvan A, Hare TA, Parra CE, Penn J, Voss H, et al. (2006) Earlier development of the accumbens relative to orbitofrontal cortex might underlie risk-taking behavior in adolescents. J Neurosci 26: 6885-6892.

10) Williams JM, Dunlop LC (1999) Pubertal timing and self-reported delinquency among male adolescents. Journal of Adolescence 22: 157-171.
11) Casey BJ, Tottenham N, Liston C, Durston S (2005) Imaging the developing brain: what have we learned about cognitive development? Trends in Cognitive Sciences 9: 104-110. 